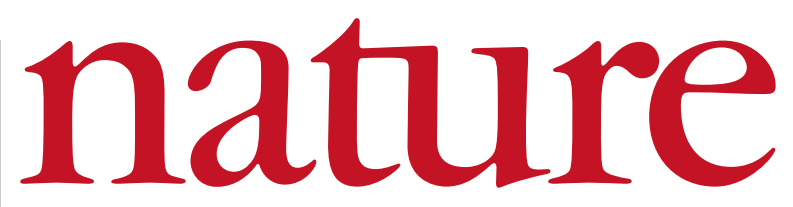

25 November 2004 Volume 432 Issue no 7016

\title{
Conscience call
}

Nuclear proliferation remains a potent threat — and scientists' active engagement is essential if it is to be effectively addressed.

$\mathrm{N}$ uclear weapons are little more than a footnote in most physics textbooks. But they live on and seem to be spreading. As this week's issue details (see pages 432 and 441), a decades-old treaty designed to stop the proliferation of nuclear weapons is beginning to unravel. All around the world, scientists are gaining the knowledge and technology they need to build a bomb. They may not be working to build a nuclear weapon today, but they are ready, should their governments ever call on them to do so in the future.

Politicians cannot be depended upon to solve this growing problem on their own. They will tend to decry the nuclear advances of their adversaries, while turning a blind eye to the progress of their friends. So it was last week, when US Secretary of State Colin Powell openly denounced the nuclear ambitions of Iran while passing through Brazil, a US ally whose own more advanced nuclear programme he has openly supported.

More than politicians, scientists have always understood the destructive power of the bomb as something distinct from its owner. The physicists who gave birth to the device recognized early on that it had the potential to ruin humanity, and many of them, including Albert Einstein and Robert Oppenheimer, took powerful, public positions against nuclear weapons after the end of the Second World War.

Like those distinguished scientists, modern researchers must take up the important work of disarmament and have much to offer in doing so. They have technical expertise that can be brought to bear on several critical issues related to stopping proliferation. In addition to developing the detectors that many governments seek to protect their ports and cities, researchers can think of techniques that further disarmament. For example, if an international treaty regulating fissile materials is ever to be created, as many arms-control experts hope, then credible technologies to track and inventory such materials must be developed.

Moreover, scientists have a unique opportunity to inform the public about the risks of nuclear weapons. Since the end of the cold war, public awareness of the world's massive nuclear arsenals has faded, even though thousands of weapons remain on hair-trigger alert. It is up to physicists, chemists, computer scientists, and all those who understand what goes into nuclear weapons, to remind the public of the devastating power of the bomb and the constant threat it poses.

Finally, and most importantly, scientists must bridge the nationalist and cultural barriers that stand in the way of disarmament. In the cold war, the scientific exchange and mutual respect shared by US and Soviet researchers helped pave the way for treaties to reduce the number of nuclear weapons held by both nations. Today, a different gap exists between developed nuclear states, such as the United States, France and Britain, and developing nations with nuclear weapons or ambitions, such as India, Pakistan and Iran. Once again, it is the scientists who must open up lines of communication and begin work towards disarmament. Together, they need to help the world arrive at a new global consensus: that nuclear weapons - regardless of whose hands they are in - pose a threat to every nation's security.

Is it realistic to expect that the world can someday be free of the bomb? Perhaps not, but researchers everywhere owe it to future generations to move us further in that direction. In the words of the great Soviet weaponeer-turned-humanitarian, Andrei Sakharov: "The conscience of the contemporary scientist cannot distinguish the suffering of his contemporaries and that of posterity."

\section{Google Nouveau}

On the Internet, 2004 promises to be a vintage year for searching.

$\mathrm{O}$ $n$ the third Thursday of November, wine enthusiasts the world over traditionally race to be first to try out l'arrivée of Beaujolais Nouveau, a barely fermented wine that has rewarded harvest workers for seven centuries. This year, the same Thursday saw a second race as scientists and other information addicts rushed to try out a new vintage: 'Google Scholar', a test version of Google search that restricts web searches to academic texts (see page 423).

That the arrival of Google Scholar is an 'event' can be sensed from the waves of giddy excitement across Internet discussion groups as people posted their own musings on the free service. By its sheer scale and functionality, Google Scholar is a disruptive technology heralding profound changes in the way that many will access scientific information.

Google deserves congratulations. With a speed that only the private sector can deliver, it has addressed the most basic need of users accessing the literature: the ability to search the full text of a broad swathe of scientific information, cutting across publishers, journals and other sources. Two reservations: some publishers have not made their text available, and Google has not yet indexed all of the text made available to it by others, including Nature Publishing Group.

But Google's database is orders of magnitude bigger than anything that exists today, and its search algorithms comparatively of lightning speed. The top search hits are the most cited — your search results won't be clogged by pages of poorly cited papers - and, in a further tweak, the hits at the top are those that are most cited by journals that themselves are the most cited.

Some worriers, including more than a few librarians, fear that Google Scholar will push scientists and students further towards what one describes as a "trend towards sloppy Internet-based research", instead of professional searches using abstracting and indexing databases, often bought at great cost by libraries. There is a grain of legitimate, if exaggerated, concern here. But one lesson of the Internet is that expensive, centralized ways of doing things tend to get undercut.

Google Scholar is far from perfect — it lacks basic functions such as search by date, characteristic of more costly databases. But the latest offering from Château Google is young, and will no doubt spur further innovation and competition in search. We at Nature drink to that, and look forward to the surprises that future years will bring. 